The final day, devoted to "General Applications" of gas chromatography, was introduced by A. I. M. Keulemans, who described some of the results, using chromothermography, obtained by Prof. A. A. Zhoukhovitsky in the U.S.S.R., By passing a ring furmace along the column during elution of the components it is possible to obtain symmetrical peaks using gas-solid chromatography at high sample concentrations. The technique enables samples of wide boiling-range to be examined, and has the added advantage that the temperature gradient and speed of the furnace offer additional parameters for controlling the separation.

The morning session was concerned mainly with the gas chromatography of inorganic compounds. Following a paper by G. Freiser describing the separation of the volatile chlorides of tin, titanium, niobium and tantalum at $200^{\circ} \mathrm{C}$. on a 'Chromosorb' column coated with squalane, A. I. M. Keulemans mentioned that he had also separated volatile metal chlorides on an aluminium chloride-coated carbon column at temperatures up to $350^{\circ} \mathrm{C}$. Both W. W. Brandt and J. Janak reported separating metals in the form of their acetylacetonates.

The chromatography of corrosive inorganic halogen compounds was the subject of two papers. T. R. Phillips employed a polytetrafluoroethylene capillary column coated with ' $\mathrm{Kel}-\mathrm{F}$ ' oils to separate mixtures of hydrogen fluoride, chlorine and chlorine trifluoride. A hydrogen-flame ionization detector, in which a platinum ring was maintained at red heat in the lower edge of the flame, was found suitable for detecting such inorganic compounds. Details of an apparatus incorporating a katherometer and automatic sampling valve, developed over a number of years for the analysis of plant streams containing highly reactive inorganic halide vapours, were given in a paper by $\mathrm{G}$. Iveson.

Many other new and interesting applications of gas chromatography were described. J. Tranchant gave some results on the use of gas-solid chromatography for the qualitative and quantitative analysis of mixtures containing nitrogen oxides, and D. W. Hill described the application of gas chromatography to anæsthetic research. An illustration of how detailed information on gasolines may be obtained by a combination of liquid-solid and gas-liquid chromatography was illustrated by a number of chromatograms in a paper presented by S. T. Griffiths. C. G. Scott gave details of a method for investigating the stability of white oils. The oxidation products of low molecular weight are eluted with a stream of nitrogen, condensed in special traps and examined chromatographically.

In a discussion in which retention volume data were mentioned, J. F. Smith outlined a useful practical method for expressing all retention volume data relative to one standard 'theoretical' nonane.

In connexion with work on compounds of high molecular weight, J. Janak described how the composition of non-volatile materials could be investigated by the gas-chromatographic analysis of their pyrolitic products. The use of esters as high-temperature polar stationary phases for examining products encountered in polymer production was discussed by R. E. Roland-Jones, and two materials, polyethylene glycol adipate and ethylene glycol distearate, were found suitable for use at $250^{\circ} \mathrm{C}$. C. G. Scott stated that he had been able to elute hydrocarbons containing up to fifty carbon atoms using alumina modified by treatment with alkali metal hydroxides as the column packing.

In the final paper of the meeting, G. R. Boreham described an apparatus suitable for fuel-gas analysis, which had as a special feature a multicell thermal conductivity cell that enables four columns to be operated in series with a detector at the outlet of each.

The meeting ended with an excellent summing up of the symposium by C. S. G. Phillips and a closing address by $R$. C. Chirnside, president of the Society for Analytical Chemistry.

${ }^{1}$ Khan, M. A., Nature, 186, 800 (1960).

\title{
ION EXCHANGE
}

$\mathrm{O}$ N December 2, the Permutit Co., Ltd., demonstrated a new film entitled "An Introduction to Ion Exchange". The programme was introduced by Mr. Walters, who gave a brief outline of the development and uses of ion exchange procedures, mentioning in particular the preparation of acidresistant anion exchange resins. The film, which is in colour, commences by illustrating some of the uses of ion-exchange resins, including the production of potable water from sea water. On the molecular scale, the structure of polystyrene-based cation and anion exchangers is demonstrated using conventional atomic models, with the exchange process simply illustrated. On the macroscopic scale, the hydrophilic nature of dehydrated resin beads is shown by wetting them, followed by observation of the resultant swelling.

The three main operations of ion-exchange are then examined : (a) Separation. Here two coloured organic ions in solution are allowed to flow through a resin column. While the blue concentrates in a narrow band near the top of the column, the red is less strongly held, forming a wider band which could be eluted. (b) Substitution. The effect of passing a solution of potassium permanganate through a resin column in the chromate form is shown by a change in the colour of the solution from purple to yellow. (c) Removal. In this case a solution of a salt with two coloured ions, copper dichromate, is allowed to flow through a mixed-bed exchanger, resulting in the production of colourless 'de-ionized' water.

The exchange process is followed in more detail by a combination of demonstrations using copper dichromate and animated diagrams of sections through a resin bead in a flowing solution. A final survey of industrial aspects of water treatment completes the film.

Colour cinematography is an ideal medium for showing ion-exchange experiments, and in this sense the film is entirely successful. Nevertheless, although an attempt is made to discuss the mechanism of ion-exchange, a more critical and scientific approach would have been desirable. In particular, specific examples, in which the equilibria involved were considered in terms of quantitative data, would 


\section{N. 4753 January 7, $1961 \quad$ N A T U R E}

have been valuable. Perhaps the most elegant use of ion-exchange is in the separation of the lanthanide and actinide elements. This aspect is almost completely ignored. Again, although emphasis is laid on the low conductivity of 'de-ionized' water, particularly by comparison with distilled water, an indication that the conductivity of laboratory distilled water is due almost entirely to dissolved carbon dioxide and ammonia would not have been out of place. Further, the 'de-ionized' water contains significant quantities of organic impurities, some of them surface-active and not detected by conductivity measurements. The film will certainly appeal to many potential users of ion exchange; whether it will appeal to students and research workers remains to be seen. "An Introduction to Ion Exchange" is a $] 6-\mathrm{mm}$. film with an optical sound track, and runs for $27 \mathrm{~min}$. Jt is available on free loan to learned societies, colleges and schools, industrial associations, etc. ; applications should be sent to the Permutit Co., Ltd., Permutit House, Gunnersbury Avenue, London, W.4.

\section{SERVICE WITH OVERSEAS GOVERNMENTS}

$\mathrm{N}$ EW arrangements for service with overseas governments are detailed in a White Paper issued by the Secretary of State for the Colonies*. For reasons indicated in an appendix, the British Government has rejected as impracticable the idea of an Overseas Service based on the United Kingdom. Such a Service would not solve the problem of the future prospects of members of the Overseas Civil Service, but the Government is examining the feasibility of establishing a Commonwealth Advisory and Technical Service as suggested by the Select Committee on Estimates. Under the new arrangements the Government will assume full responsibility for the cost of the inducement element, which is a necessary part of the emoluments of most expatriate officers, and a fresh review of the emoluments of the officers concerned will be necessary in many territories. For purposes of United Kingdom taxation, the additional pension payable to an expatriate officer, which stems from the inducement allowance, will be treated in the same way as existing pension, and the cost of that part of the pension will be borne by the Government. The Government will pay education and children's allowances similar to those payable to members of the Home Civil Service posted overseas, and will also meet half the passage costs required to enable children being educated outside the territory in which an officer is serving to visit their parents, or to be visited by their mother, once a year. The Government has also contributed to some compensation schemes now in force for loss of career on premature retirement, or taken account of their cost in considering what further financial assistance should be given, and for future schemes will share the cost equally with overseas Governments.

The scheme will come into effect in most territories on April 1, 1961, and will cover up to 21,000 pensionable and contract officers overseas at a cost to the British Government of $£ 12-£ 16$ million a year. Besides all existing Colonies and dependencies, it will be offorod to Nigeria, Sierra Loone and Singapore, and to Northern Rhodesia, and Nyasaland, but not to the Bahamas, Bermuda, Brunei and Hong Kong, where, for several reasons, this form of help is not regarded as appropriate, at least for the time being. The arrangements have been developed after consultation with overseas governments and staff associations and they are complementary to plans being vigorously pursued for staffing the public services by local

* Colonial offlce. Service with Overseas Governments. Pr. 22 (Cmnd, 1193.) (London: II.M. Stationery Office, 1960.) 1s, 3d. net. officers in the territories concerned. The White Paper also emphasizes the value of overseas officers in technical assistance schemes, and a high-level technical assistance working party has been set up under Foreign Office chairmanship as a means of exchanging information and experience between departments and organizations engaged in technical assistance work. A sub-committee of this body will co-ordinate the recruitment activities of the Government for technical assistance posts, and the fullest consideration will be given to retiring and retired members of the Overseas Civil Service for all suitable vacancies. It is also proposed to give greater publicity to the Overseas Services Resettlement Bureau, which has already placed more than 1,000 of the 1,710 officers registered with it from July 1957 to mid-October 1960 ; it is pointed out that the Bureau could prove a very valuable source of man-power to industry and commerce, particularly to export industries seeking men and women with long and detailed knowledge of overseas territories.

As regards the future, the proportion of candidates appointed on contract terms through the Colonial Office has increased markedly in recent years and such appointments now constitute the great majority. Wherever possible the British Government plans to obtain recruits on loan from government departments, public corporations and local authorities, so that individuals can be certain of resuming their previous employment on returning to the United Kingdom. It is also hoped that individual service overseas will be accepted as an asset both to the employer and employee, and that employers will co-operate in facilitating the release of those able and willing to serve overseas and in re-absorbing them on their return.

Further to the above, the Colonial Office has now issued the report of the Public Services Conference held in London during March $1-10,1960$, to exchange information on measures taken or projected to build up local civil services in the African territories, which was initially a confidential document for consideration by the governments represented at the conference* All, however, have since agreed that it should be published, and it has now been issued by tho Colonial Office.

The agenda covered the general pooling of experience and a comparison of the measures adopted; a review of the facilities for sccondary and university

* Colonial Office. Report of the Public Services Conference held in the Colonial Office, London, 1st to 10th March, 1980. Pp. iii +25 . (Colonial No. 347.) (London: H.M. Stationery Office, 1960.) 3s. 6d. net. 